\title{
EL DETRITUS EN UN ANIMAL MUDO LEVANTA LA VISTA DE GERMÁN MARÍN
}

\section{THE DETRITUS IN UN ANIMAL MUDO LEVANTA LA VISTA BY GERMÁN MARÍN}

\author{
Bessy Brito Martínez \\ Universidad de Concepción \\ bessybto@gmail.com
}

\begin{abstract}
Resumen:
Examinamos la trilogía Un animal mudo levanta la vista del escritor chileno Germán Marín a partir del imaginario de las ruinas, en una variante de gradación residual de dicha poética en los albores del siglo XXI, en el contexto neoliberal chileno de transición a la democracia y tras la política oficial de olvido para arrasar hasta la devastación con el horror del pasado dictatorial, que tiende al detritus, al escombro o desecho, al fragmento residual (arquitectónico o alegórico) que se opone a la totalidad y continuidad del sistema hegemónico de poder que violenta al individuo. Imaginario que fisura dicho poder desde la fragmentación y la creación de un sentido otro desde la literatura como resistencia.
\end{abstract}

Palabras clave: Germán Marín, detritus, poder, violencia.

\begin{abstract}
:
We examine the trilogy Un animal mudo levanta la vista from the Chilean writer Germán Marín from the imaginary of the ruins, in a variant of residual gradation of said poetics at the dawn of the XXI century, in the Chilean neoliberal context of transition to democracy and after the official policy of oblivion to raze to devastation with the horror of the dictatorial past, which tends to detritus, rubble or waste, the residual fragment (architectural or allegorical) that opposes the totality and continuity of the hegemonic system of power that violates to the individual. Imaginary that fissures said power from fragmentation and the creation of another meaning from literature as resistance.
\end{abstract}

Key words: Germán Marín, detritus, power, violence.

Recibido: 25 de septiembre de 2020

Aceptado: 08 de noviembre de 2020 


\section{A modo de contexto}

La obra de Germán Marín (1934-2019), a pesar de su peso y densidad ${ }^{1}$ en el panorama chileno, ha tenido una recepción crítica discreta si tenemos en cuenta que se circunscribe, mayormente, a cierto sector de la academia de su país natal. Un animal mudo levanta la vista, que se completara como trilogía en 2003, conformada por las novelas El palacio de la risa, Ídola y Cartago, ha sido poco estudiada en su conjunto.

Los investigadores se han acercado, principalmente, a El palacio de la risa, con predominio en el análisis de temáticas como la memoria, con respecto a la historia dictatorial chilena. En esta línea algunos estudios se han centrado en el olvido que pretende borrar la historia reciente de Chile (Costabal), donde la Historia es fragmentación (Gallardo), en la alegoría de la derrota y la nostalgia (Moya), en la relación de la novela con la memoria involuntaria de Henry Bergson y la abolición del tiempo histórico (Rojo), o el lugar de memoria de Pierre Nora (Willem), así como la memoria de la casa como enciclopedia de las bellas artes y como decadencia (Olea). Igualmente ha sido de interés en los estudios de El palacio de la risa el tema de la violencia en las mujeres colaboradoras de la dictadura (Olea) y la presencia de la ruina como contemplación de los restos de Villa Grimaldi y la extrapolación al país (Gallardo), como intento del poder de borrar la memoria (Costabal), desde los escombros activadores de la memoria involuntaria (Rojo), en la degradación del arte en espectáculo (Olea) y desde la casa como perversión del idilio en horror (Willem).

\footnotetext{
${ }^{1}$ En 1973 Marín debuta con Fuegos artificiales (novela). En el exilio en México publica el libro gráfico Chile o muerte (1975), Cicatrices: papeles de Santiago (1976) y la investigación Una historia fantástica y calculada (1976). En 1976 se traslada a Barcelona. Tras su regreso a Chile en 1992 publica la trilogía Historia de una absolución familiar (novela, premio de la Crítica del Consejo del Libro) que incluye Círculo vicioso (1994), Las cien águilas (1997) y La ola muerta (2005). En 1995 publica El Palacio de la Risa, primera novela de la trilogía Un animal mudo levanta la vista (2003), que se completa con Ídola (2000) y Cartago (2003). Compila El circo en llamas (1997) con artículos de Enrique Lihn. Publica Conversaciones para solitarios (cuento, 1999, Premio Municipal de Literatura de Santiago), Lazos de familia (cuento, 2001), Carne de perro (novela, 2002), Basuras de Shangai (cuento, 2007; Premio Atenea, 2008), La segunda mano (novela, 2009), Compases al amanecer (cuento, 2010), Dejar hacer (novela, 2010, Premio Municipal de Literatura de Santiago), Antes de que yo muera (2011), Últimos resplandores de una tarde precaria (antología de cuentos, 2011), El Guarén. Historia de un guardaespaldas (novela, 2012), Notas de un ventrílocuo (novela, 2013), Tierra amarilla (novela, 2014), Adiciones palermitanas (novela, 2016), Bolígrafo o los sueños chinos (novela, 2016), Tal vez sí, tal vez no (novela, 2017), Póstumo y Sospecha (novela, 2018) y Un oscuro pedazo de vida (cuento, 2019).
} 
Sobre Ídola ha suscitado interés el análisis de la búsqueda del origen en el recuerdo y el arte, insertado el sujeto en el fetichismo de la imagen neoliberal; la violencia en el cine porno, en la violación de pareja y en el castigo del sistema de disciplinamiento, así como el simbolismo del terremoto como destrucción del orden neoliberal (Barreto). Simbolismo que también apunta Bárbara Soto (2004) en su estudio de la degradación del intelectual por el vacío capitalista de la ciudad-sexo.

Solo dos críticos se han aventurado en el estudio de la trilogía. Daniela Aguilera (2013) en cuanto a la degradación moral, sexual, intelectual y escritural del sujeto por la inserción en el sistema neoliberal, salvando solamente de la degradación a la memoria del individuo. Andrea Kottow (2010) analiza la trilogía no solo relacionada con la historia chilena sino como exponente de la catástrofe existencial moderna y la pérdida del individuo de su esfera protectora (partiendo de los postulados del filósofo Peter Sloterdijk y su concepto de burbuja diádica que protege al individuo de las amenazas exteriores), en un Post-Apocalipsis de destrucción donde la historia chilena está rota y el individuo no puede reconstruirla, por lo que la trilogía transita de la pérdida de la unidad, al intento inútil de recuperación, a la conclusión de la imposibilidad de restitución.

Esta trilogía de Marín, ubicada temporalmente en la última década del siglo XX, tiene un sustrato en la historia pasada reciente del Chile dictatorial (1973-1990), y sus consecuencias para el individuo durante la democracia en la década del noventa. Amplio contexto que permite apreciar variedad de posturas, oficiales y contraoficiales, en relación al pasado bochornoso, desde un presente en pleno desarrollo del sistema neoliberal, propiciador de la devastación del pasado. Una parte de la literatura chilena mostró resistencia al discurso hegemónico de los gobiernos de concertación en la lógica del olvido para desaparecer los vestigios del terror de la dictadura. Marín, por su parte, profundiza en la realidad chilena en su reencuentro (luego del exilio) con el país de la transición a la democracia, insertado en el contexto latinoamericano de lo que se ha llamado literatura postdictatorial $^{2}$. La realidad chilena de la década del noventa no puede ser comprendida en su complejidad sin recurrir al tema de la dictadura, no solo por el trauma de torturados y

\footnotetext{
${ }^{2}$ Para Idelber Avelar determinada por el duelo y la aceptación de la derrota histórica, donde predomina el discurso alegórico de la memoria. Lo postdictatorial no significa posterioridad a los regímenes militares, sino "incorporación reflexiva de la mentada derrota en su sistema de determinaciones" (27). Aunque la derrota aún permanece en el presente, en la literatura postdictatorial "se acepta como la determinación irreductible de la escritura literaria en el subcontinente" (27).
} 
desaparecidos (sobre todo en los primeros años) sino también porque el Chile en estado de excepción dictatorial implantó el modelo económico neoliberal.

Chile fue referente mundial durante la dictadura de un sistema totalitario de derecha cuya repercusión se mantuvo en la década del noventa por la reminiscencia de totalitarismo en la transición a la democracia y el reforzamiento de la política económica neoliberal. A criterio de Gabriel Salazar (2013) la transición en Chille fue la consolidación de la obra de Pinochet apoyada por "los Contreras' Boys, los Chicago Boys, los Constituent Boys y los Touraine's Boys" (94). Para el historiador Máximo Quitral los gobiernos democráticos demostraron el legado pinochetista por su sujeción a la Constitución de 1980, por los enclaves autoritarios que obligan a la aceptación y no al debate político para el desarrollo del país, así como por el espejismo del crecimiento económico sin equidad social “construido por los poderes fácticos y exacerbado por los medios de comunicación" (117).

Steve Stern realiza un estudio minucioso sobre los diferentes marcos de memoria que se alternaron durante la dictadura y la etapa transicional de la década del noventa, ya sea desde las posturas del poder hegemónico o desde la contraoficialidad. Resulta esclarecedor su análisis del marco de memoria que trabajó la oficialidad, tras el golpe militar. Este se basó en la idea de restauración del orden y los valores nacionales perdidos en el gobierno de Allende y la utopía ${ }^{3}$ de salvación de un mal mayor que constituía el comunismo, catástrofe que conducía al país "hacia la ruina y la violencia" (302). En la lógica de la Guerra Fría, el nuevo poder militar construye una imagen de los comunistas como el enemigo interno (extremista, destructor, amenazante, violento, traidor a la patria y hasta extranjero), que constituye el cáncer maligno a erradicar en una guerra sucia de limpieza y purificación para elimina a los subversivos en nombre del anticomunismo. En contraste, gracias a la manipulación informativa mediática, la imagen de Pinochet es trabajada como reconstructor del Chile en ruinas, autoridad sacrificada que traerá el futuro luminoso a la nación. El presupuesto de salvación ante la ruina y la violencia del comunismo, le aportaba

\footnotetext{
${ }^{3}$ Aunque no se profundiza en el concepto de utopía, esta es mencionada en relación a los mecanismos del poder dictatorial. Se entiende la utopía desde su configuración clásica como doctrina de lo que no es en ninguna parte, como proyección en el presente hacia un ideal de perfección casi imposible en el futuro y desde una perspectiva ya problemática en la posmodernidad determinada por "la acelerada demolición de sueños y esperanzas" (Aínsa 17). Sin embargo, no se desarrollará el concepto en relación con la trilogía, sino solamente como posibilidad de la literatura de abrir resquicios personales esperanzadores para la creación de sentido contrapuesto a las dinámicas del poder (Nancy).
} 
al régimen dictatorial un manto de legalidad para justificar los excesos violentos en función del progreso posterior. Así se establecía una equivalencia entre violencia y salvación de la violencia, que rompería en pedazos el mito de excepcionalismo chileno y su capacidad de resiliencia política ${ }^{4}$.

Stern explica que cuando este marco de memoria oficial comienza a perder credibilidad en la década del ochenta y se fortalecen otros marcos de memoria contraoficiales de ruptura y disidencia, desde el poder se asume la estrategia de la memoria como caja cerrada, de olvido y amnistía, "un entierro deliberado del pasado oscuro" (302). Esta postura oficial es propiciada por una cierta prosperidad económica en los años ochenta con la novedad de la política económica neoliberal que insta al consumismo, a la conformidad, a una cultura de superficialidad sin conciencia moral; a partir de la cual el pasado es asociado a los malos tiempos que deben ser olvidados, y el presente y el futuro entrañan un componente esperanzador. Aunque Pinochet pierde el plebiscito en 1988, Stern asegura que la realidad de los noventa evidenció la continuidad de un proceso, pues la democracia estuvo ensombrecida por el legado de la dictadura, de miedo y violencia, el no estatismo de la política económica neoliberal, la despolitización de la cultura tecnocrática, la presencia poderosa de los militares (21-22), así como por un impasse de la memoria, frenada por el poder y la esquizofrenia moral (32).

Idelber Avelar se refiere a cómo la literatura postdictatorial pone el presente en crisis como aceptación de la derrota, de la memoria de los muertos, desde un tratamiento alegórico de la otredad, en contraposición a la lógica sustitutiva de la forma de memoria del mercado donde la mercancía termina siendo desechada pues lo viejo es reemplazado por lo nuevo y el pasado es pensado como "operación sustitutiva sin restos" (13). Así la literatura postdictatorial, de la que Marín es partícipe, ante la lógica el mercado neoliberal (que se constituye en el nuevo poder hegemónico de fines de siglo), mantiene el efecto del pasado sobre el presente para mostrar el resultado residual que dicho pasado ha generado. Contra la lógica de un pasado sin restos, la trilogía de Marín critica al sistema neoliberal que incita a

\footnotetext{
${ }^{4}$ El criterio de Gabriel Salazar contradice en parte la idea de Steve Stern del excepcionalismo y el constitucionalismo democrático como esencia chilena anterior a 1973, pues afirma Salazar que la imposición violenta del cambio fue una constante durante doscientos años en Chile, como parte de su normalidad, de su mito patriótico (14), por lo que la tiranía sería patológica, "enfermedad congénita" (29), y nunca habría existido en Chile un verdadero régimen aristocrático o democrático, sino oligárquico, demagógico, de "tiranías francas o encubiertas" (14).
} 
arrasar con la historia pasada bochornosa hasta la destrucción, hasta convertirla en detritus, y que degrada al individuo en una continuidad de la violencia que muta en democracia. Al tiempo que las novelas habilitan una lectura fragmentadora de la continuidad del poder hegemónico mediante la resistencia en la creación de sentido que aporta la literatura.

\section{Cuando solo quedan mínimos vestigios}

El estudio del imaginario de las ruinas se asume en este artículo desde una perspectiva múltiple que -a diferencia del entendimiento más generalizado que vislumbra la ruina desde el plano físico arquitectónico- la define como decadencia en varios niveles, ya sea física arquitectónica, social, histórica, ideológica o personal (y esta a su vez puede ser física, moral, intelectual). Ideas afines a las nociones de ruina y decadencia se mezclan en un campo semántico donde entran términos tales como caída, pérdida, degradación, destrozo, devastación, resto, vestigio, deshecho, escombro, basura o detritus, en una evidente gradación que se acerca a la mínima expresión fragmentaria, que cada vez se aleja más de la totalidad, lo cual aporta riqueza de matices en el análisis de la obra literaria.

Si bien un autor clásico como Georg Simmel (2002) profundizó en la ruina arquitectónica y su compleja relación entre las fuerzas ascendentes de la voluntad humana (el espíritu) en la construcción y las fuerzas mecánicas descendentes (la naturaleza) en el deterioro ruinoso, como pugna entre lo transitorio y lo permanente, otro de los teóricos clásicos, Walter Benjamin (2010), tiene un concepto de ruina más abarcador, estrechamente relacionado con la decadencia, con la alegoría, con el descentramiento de la historia de los vencidos portadores de las derrotas del pasado, desde una perspectiva ponderadora del fragmento histórico, destructor de la totalidad de los sistemas hegemónicos y el continuum de la historia. Mabel Moraña (2018) destaca la mirada oblicua de Benjamin, de discontinuidad, de desarticulación de los discursos legitimadores del poder.

Andreas Huyssen, por su parte, reivindica el interés, en el tránsito del siglo XX al XXI, por temas del recuerdo, del pasado, en una relación historia-memoria conflictiva, donde las fronteras temporales se difuminan y el pasado se convierte en parte del presente. Sin embargo, asegura que el siglo XX propició la obsolescencia de las ruinas auténticas y que, por tanto, en el siglo XXI la era de las ruinas inevitablemente ha llegado a su fin: "Las 
cosas, transformadas en mercancías, envejecen mal. Se vuelven obsoletas, son tiradas a la basura o recicladas [...] En la era del turbocapitalismo, las cosas tienen pocas posibilidades de envejecer y convertirse en ruinas" (36), por lo que sobreviene el escombro: "La ruina del siglo XXI es detritus o restauración" (36).

La primera novela de la trilogía de Marín, El palacio de la risa (1995), comienza precisamente con un sujeto ante los restos de lo que fuera Villa Grimaldi, la cual no puede ser considerada siquiera una ruina pues de la antigua mansión solo quedan escombros, residuos, astillas en un "sitio eriazo invadido por la maleza" (187). A su regreso a Chile como extranjero de su propio país, el protagonista solo encuentra "detritus" (102), evidencia de "lo que ya no existía" (101). La casa de su recuerdo ha sido completamente devastada por una "mano furiosa" (97), alegoría del poder totalitario que violenta desde la destrucción, para borrar la historia de crímenes que allí se sucedieron mediante una "política de tierra arrasada" (166) que no deje huellas.

La degradación de la mansión ha sido progresiva en varios períodos de la historia chilena, como por ejemplo a inicio de los años setenta, durante el gobierno de Allende, con la creación de una discoteca, donde Villa Grimaldi pasa de realidad a apariencia. Pero es durante el régimen dictatorial de Pinochet que llega a una decadencia mayor, bajo el poder totalizador que la convierte en uno de los principales centros de tortura de la DINA, donde acababan los "enfermos que debían recibir una acción terapéutica" (173), para garantizar la limpieza y la organización del país.

El centro de torturas de Villa Grimaldi hace palpable los postulados de Giorgio Agamben (2017) sobre el homo sacer, como representación de la nuda vida, de la vida reducida a lo biológico, desnuda, abandonable y sacrificable, sobre la cual existe total libertad del soberano para decidir si el individuo vive o muere sin que sea considerado un delito. Por lo que en la antigua mansión se practica una violencia divina como la entiende Walter Benjamin (2010), destructora del derecho, "violencia sobre toda vida en nombre del viviente" (177).

Bajo los presupuestos de la tipología que desarrolla Slavoj Žižek (2009) sobre la violencia, en la primera novela de la trilogía predomina la violencia subjetiva que es la más claramente visible, porque se sale del nivel de normalidad y es practicada por individuos representantes de un aparato represivo bien identificable del poder hegemónico. La 
violencia a que es sometido el individuo como resultado del poder totalitario El palacio de la risa (1995) tiene tanto componentes físicos como psicológicos. Se practican variadas torturas como Pau de Arara, la inmersión en agua, la Campana, la Torre de los Suplicios, la electricidad o el confinamiento en pequeños espacios, que parten de la fragilidad corporal: "El cuerpo resultaba una maldición, sometido entre esas violencias a unas funciones diarias coartadas, por lo que es lógico suponer [...] que ninguno de los presos se salvó de sentir en esos días, cuando el organismo a pesar de todo reclamaba desahogarse, la débil condición humana" (106).

Por su parte, Wolfgang Sofsky (2006) coincide con Benjamin al identificar el poder con la violencia física ya que esta afecta al cuerpo, el cual considera que es el centro de la existencia. Para Sofsky el dolor físico desmiente el "principio esperanza" (77) y la tortura constituye una violencia habitual y absoluta, repetitiva, una eficaz práctica del régimen omnipotente para obtener docilidad y arruinar al torturado. Así en la novela (1995) la tortura física lleva a la tortura psicológica, al miedo constante de "la eternidad del castigo" (169). El sujeto termina arruinado por completo, con la voluntad anulada. Gabriel Giorgi (2014) se refiere al homo sacer de Agamben como degradación y pérdida de la dignidad humana en la bestialización (180), en una distinción entre persona y no-persona. De esta manera en la novela de Marín (1995) los prisioneros son aniquilados como personas. La falta de higiene o la necesidad de alimentos los convierte en bestias: "era común [...] invitar a algunos detenidos a aprovechar las sobras de la comida, en competencia con los perros, pues no había que perder oportunidad en hacerles sentir la derrota. La humillación resultaba a veces mejor que una paliza y [...] provocaba una desvalorización de sí mismo que ayudaba a manipular su voluntad" (181).

No solo los sujetos torturados resultan arruinados en la novela. Villa Grimaldi toda se alegoriza como "basural humano" (172). Algunos colaboradores fueron antes prisioneros, como es el caso de Mónica, antigua amante del protagonista. Su traición la obliga a "anular el pasado" (162). Nadie se salva de participar en la violencia de la tortura, incluso de experimentar placer en el acto. María del Carmen, psicóloga colaboradora de la DINA, termina siendo una "piltrafa" (170), corrompida, temblorosa y avejentada. Vive escondida con desasosiego, con miedo a la venganza por la violencia que rememora en una especie de representación teatral donde se disfraza de santa degradada que solo logra enajenarse 
viendo en la televisión la novela La reina de la chatarra (título también alegórico sobre su condición). Su travestismo (del horror de la violencia a la beatificación del disfraz) es analizado también por Catalina Olea (2014) en relación directa con la circunstancia del país en transición, que enmascara la permanencia dictatorial violenta.

El propio protagonista es un sujeto desechable. $\mathrm{Su}$ condición residual ha sido generada por la catástrofe que significó en su vida la escisión provocada por el golpe militar. El exilio, con un trabajo mediocre y un matrimonio desdichado, constituye una derrota, el fracaso de la ilusión que abre paso a la razón. Sin embargo, el regreso al país constituye otro destierro pues la realidad devastada que encuentra a su regreso lo hace sentirse extranjero, "el resto solitario de un naufragio" (98), falto de motivaciones literarias, invisible en un país que "deseaba borrar el pasado de cualquiera posible mácula y hacer cuentas nuevas" (97-98).

A diferencia de la voluntad mayoritaria del Chile de los noventa que encuentra a su llegada, el protagonista se adentra en una búsqueda nostálgica (gatillada por la devastación de Villa Grimaldi) que alterna el recuerdo de diferentes etapas tanto de su historia personal como de la historia de Chile (encarnada en la historia de la casa), pues afirma que "no venía del extranjero, sino del pasado" (97). La nostalgia se despliega como una búsqueda policial para desentrañar los derroteros de Mónica en relación al horror de Villa Grimaldi y para criticar tanto el pasado violento totalitario como el presente falto de memoria, desde la posibilidad de la escritura como forma de sobrevivencia.

El palacio de la risa hace evidente que en el capitalismo tardío no procede hablar de ruinas sino de residuos, de escombros, como propone Huyssen. La máquina excavadora que en la novela de Marín (1995) deja devastada la antigua mansión, es alegoría del sistema totalitario y neoliberal que destruye al ser humano y a la sociedad chilena hasta que solo queda el detritus, como resultado de una historia que ha quedado escindida por el horror al pasado y la aceptación de la infamia con una "paz sin justicia" (191) y por la postura no reconstructiva del pasado sino de fundación constante: "Santiago no era una ciudad que se dejara moldear por la historia como había comprobado al observar la presencia de nuevos edificios y el desfiguramiento de barrios enteros. Tenía la vocación de fundarse permanentemente" (99-100). Al final de la novela, se deja entrever lo que será medular en el resto de la trilogía: la devastación social de violencia de las poblaciones marginales y el 
malestar social generado por el neoliberalismo y la política reconciliatoria, que "echaban a perder el discurso triunfalista tan en boga" (196). Así, cierra la primera novela con el "agua sucia del canal" (198), alegoría del Chile turbio de la década del noventa.

Tanto en Ídola como en Cartago se advierte cómo la violencia, generada por las voluntades de poder, no desaparece durante los gobiernos democráticos, sino que muta en nuevas facetas. En Ídola (2000) el sujeto está cada vez más fracasado, derrotado, degradado en su condición intelectual. Se deja llevar durante un tiempo por la vorágine facilista del consumismo neoliberal desenfrenado de la clase media, por la enajenación de la estabilidad económica, la engañosa felicidad material impulsada desde la publicidad. En esta dinámica neoliberal, como advirtiera Iván Barreto (2007), creyéndose poseedor es poseído por el sistema.

La realidad predominante que circunda al protagonista de Ídola es lo que Byung-Chul Han (2016) denomina sociedad de rendimiento -en contraposición a la sociedad disciplinaria de Michel Foucault (1976), prohibitiva, de violencia macrofísica-, donde el nuevo poder se ejerce desde el capital y el consumo, y la violencia es cada vez más invisible, interior, aunque no se haya descartado por completo la represión externa, como también se constatará en esta novela. En la sociedad capitalista contemporánea Slavoj Žižek (2009) asegura que se despliega una violencia objetiva sistémica, de coerciones sutiles, no de individuos específicos sino de forma anónima determinada por los efectos devastadores de la circulación de capital y la falsa sensación de libertad, de libre elección que enmascara la opresión neoliberal.

En Ídola (2000) incluso los antiguos representantes de la izquierda chilena han sucumbido al "ablandamiento moral" (101) y la anestesia del dinero. Los intelectuales de prestigio de décadas anteriores forman parte de una generación de residuos, "derrotada por los acontecimientos" (101). El protagonista se siente parte de una generación no solo traicionada por la historia sino además por sí misma. Artistas como Ruiz, antiguamente documentalista durante el gobierno de Allende, carecen ya de interés por el arte o la política. Su única motivación es el diario subsistir.

La novela hace una crítica frontal el mundo literario frívolo del presente, en el cual varios han aprovechado "su posición de izquierdista de carnet" (178) en el pasado y se han afianzado en el presente gracias a una retórica hipócrita de "socialista burgués" (178). 
Aunque Marín incluye algunos pocos personajes en la novela que se mantienen derrotados pero que no se suman al juego del consumismo, como son los casos de Eduardo Lihn o el gordo Ossa.

El protagonista se inserta en el sistema neoliberal a través de la escritura de guiones para la producción de cine porno. Aquí su escritura se degrada no solo por convertirse en mero instrumento utilitario sin pretensiones artísticas, sino porque esta se torna desecho ante la preponderancia de la imagen cinematográfica. El submundo de la pornografía, sórdido y violento, contrasta con el paraíso enarbolado por la imagen neoliberal de los malls, vendida por la propaganda televisiva. Sin embargo, el sujeto protagonista cede ante este mundo por la necesidad de dinero y se vuelve un camaleón para obtener la "platita dulce cada mes" (16-17). Byung-Chul Han (2016) se refiere a la violencia de la positividad del consenso del capital, lo que genera una falta de conflicto y conduce a la desideologización en la sociedad de rendimiento. En esta las antiguas luchas de clases devienen obsoletas pues ya no prevalece la violencia del disenso, sino la del consenso en relación al dinero. En esta época en que la política carece de gloria y poder, el poder se vislumbra principalmente en el capital y en el consumo.

Así Ídola (2000) revela un Santiago dispar, de relajación consumista pero sobre todo de pobreza, podredumbre moral, marginalidad y muerte. La organización detrás de la producción porno trabaja bajo los mismos preceptos violentos de la dictadura. El actor David Calisto, antiguo ayudante de la DINA, tiene métodos similares a la tortura y llega al asesinato, la desaparición y abandono de los cuerpos de las jóvenes víctimas de la necesidad material. Estas mujeres son tratadas como basura humana, desechos, bofes, al igual que sucedía impunemente durante la dictadura. El protagonista experimenta la vileza en carne propia. Aprende, por interés, a mirar hacia otro lado; se limpia de responsabilidad (como los torturadores del pasado). Asume su labor con la normalidad de lo habitual: "El trabajo constituía una rutina semejante a la actividad de un policía en un sótano de interrogatorios" (171). Esta semejanza del trabajo (aunque clandestino) durante la democracia y los procedimientos de la dictadura, confirman un proceso de continuidad en la violencia, aunque enmascarada bajo otras formas, con un fin mercantil.

El alcance de la Organización no es limitado, ni lo que en ella se ejecuta puede ser circunscrito a un hecho aislado. Su influencia llega a las altas esferas del poder, dada la 
complicidad y el encubrimiento de la policía. Cuando sale a la luz el escándalo de los psicópatas de Maipú, la violencia una vez más trae la solución, como ocultamiento de las huellas de los crímenes, modus operandi heredado de la dictadura. Es por eso que el protagonista afirma que "la sangre en Chile ayuda a limpiar" (188). El poder de la Organización se manifiesta como "mano invisible", como "poder en las sombras" (188), lo que provoca mayor incertidumbre en el individuo por el hecho de no enfrentarse a un enemigo reconocible directamente. Asimismo se siente desprotegido ya que, en plena democracia, persiste el fantasma del totalitarismo pues, como asegura el protagonista, las “estructuras destinadas a velar por el orden ciudadano olían a sangre desde hacía muchos años" (192).

David Calisto y Julia Quesada, quienes son solamente las caras visibles de la Organización, son asesinados para acallar la opinión pública y una vez más dejar todo en el olvido. Se trata de eliminar a todo testigo mediante "unas muertes llamemos fortuitas, tan comunes en los ambientes de la mafia" (13). En un intento de asesinato, el protagonista resulta lesionado pero salva la vida. En el incidente se describe cómo el impacto del automóvil lo lanza contra la acera como si fuera una "bolsa de basura" (210). Así el sujeto residual sobrevive pero tiene que arrastrar con las secuelas de por vida. Sin embargo, el poder real detrás de la Organización pornográfica permanece siempre oculto e intacto. En complicidad con la prensa manipuladora y subordinada a las instancias del poder, el escándalo criminal pronto es remplazado con otra noticia de actualidad.

El protagonista, quien encontrara la satisfacción sexual en la idolatría del sexo de Sofía y practicara una sexualidad heterodoxa a partir del quiebre de la dicotomía masculino-femenino, se deja llevar también por la violencia en su relación. Fruto de la violación a Sofía nace el hijo monstruoso, Asmodeo. Este es rechazado por su madre e impulsa la decadencia de la pareja hasta que el vínculo se diluye finalmente, reforzado por el rencor de la violencia. Ya hacia el final de esta novela el protagonista no es más que un despojo enfermo sin alternativas, un viejo atrofiado en una ciudad igualmente residual.

En Ídola no solo se hace evidente una violencia objetiva sistémica (Žižek) producto de la economía neoliberal, sino también una violencia subjetiva, como reminiscencia del totalitarismo dictatorial. Marín indaga en cómo la dictadura extendió hasta la democracia en los años noventa su herencia lúgubre de podredumbre, residuos y devastación moral, 
aunque bajo el disfraz de prosperidad económica. El contexto de la novela es eminentemente transicional, pues si bien aparecen elementos de la sociedad de rendimiento a la que se refiere Byung-Chul Han (2016), todavía perviven solapados rezagos de la sociedad disciplinaria que describiera Michel Foucault (1976).

El terremoto con que comienza el texto, que deja en escombros a la ciudad de Santiago, evidencia todo el sustrato violento de una sociedad aparentemente pacífica y reconciliada: saqueos, fugas de reclusos y locos, militares desertores armados, violaciones, bestialización, restos de cadáveres despojados en la calle y devorados por los animales. Entre los residuos de la catástrofe la moral se resquebraja: "todo resultaba legítimo o, al menos, permitido, al ser el caos superior al orden y cesar las normas establecidas" (25). La devastación es tanto física como moral y a la vez alegoría de la posible destrucción del sistema neoliberal que se sostiene en Chile sobre el dinamismo constante que incita al olvido, a partir de la demolición tanto de las casas ruinosas como del pasado muerto, y la correspondiente suplantación mediante la construcción de nuevos edificios residenciales o supermercados.

La decadencia se hace evidente también en el posicionamiento de la prensa que, tras el desastre, silencia la destrucción. En su relación de complicidad con el poder hegemónico, su postura es de "dudosa tranquilidad" (26). Las noticias solo tratan temas económicos y meteorológicos, aunque con una referencia encubierta en la mención de "un sol moralmente brumoso" (27). La democracia tiene como una de sus banderas la libertad de prensa y la ausencia de censura para posibilitar las opiniones contrapuestas y el reconocimiento de la divergencia como uno de los derechos individuales a salvaguardar. Sin embargo, el posicionamiento exclusivamente oficialista de la prensa en la novela, corrobora que las voluntades de poder en el Chile democrático siguen siendo totalitarias y represivas, continuidad de la dictadura.

El terremoto, con su inevitable conclusión residual de solo restos y desechos, donde prácticamente nada queda en pie (física y alegóricamente), es la "amenaza suspendida sobre cada chileno" (19). Así, esta amenaza constituye la inminencia perenne de la violencia, a la vez que puede configurarse como posibilidad de fragmentación alegórica del poder hegemónico. Hecho que podría propiciar finalmente que todo se fuera "al tarro de basura" (22) y los chilenos quedaran libres de la represión, al tiempo que sufrieran el 
castigo con la catástrofe. En Ídola el terremoto pareciera estar evocando una especie de castigo merecido de los chilenos, por haber sido cómplices de la violencia y la desmemoria. Así también se configura como posibilidad alegórica de ajustar cuentas con el pasado a partir del detritus.

En la última parte de esta trilogía de Marín, Cartago (2008), el sujeto ha llegado a un nivel de devastación tal que se encuentra recluido en una institución psiquiátrica, sin posibilidades de salir y con prácticamente nulo vínculo con el exterior. Su caída, que venía perfilándose desde El palacio de la risa, se concreta tras una serie de acontecimientos que lo llevan finalmente al asesinato. Ha convivido con su hijo muerto, luego se ha deshecho de su cadáver en el río Mapocho; ha tenido una relación afectiva primero con un maniquí y luego con un residuo de un cuerpo, El Brazo, encontrado en los escombros de Villa Grimaldi; relación que asume desde la aceptación de la fragmentación corporal como metonimia que evoca el todo escindido por la violencia dictatorial.

A este "ex chileno con vocación apátrida" (18) no le queda más remedio que conformarse con los despojos, tanto ajenos como propios. Él mismo no es más que un vestigio de lo que fuera. Al deterioro propio de la vejez y los achaques producto del intento de asesinato de la Organización, se le suma en esta novela la decadencia mental, la locura, la cual constituye el punto culminante de todas sus otras decadencias: corporal, ideológica, sexual, económica, intelectual y moral.

El entorno de este sujeto residual no puede ser otro que una casa atestada de desechos ajenos. Antes de ser encerrado habita un chalé deteriorado, lleno de restos de una vida familiar abandonada por sus antiguos dueños, donde los despojos constituyen una presencia fantasmal más duradera que los propios habitantes. La "vocación carroñera" (35) del protagonista, de sobrevivencia dentro del detritus, contrasta con la otra cara oficial de la realidad chilena, de progreso inmobiliario, de constante construcción de nuevos conjuntos habitacionales que ensombrecen las antiguas mansiones. La realidad exterior, de la cual no forma parte ya, es hostil al protagonista y está en permanente mutación, intensificada por la llegada de extranjeros y la actividad constante de obreros de la construcción que parecen robots por el automatismo de su trabajo repetitivo y de sus vidas carentes de protagonismo en la "zoología social" (25). El protagonista se refiere a Santiago como ciudad fundada 
sobre un cementerio indígena, lo que constituye además una alegoría sobre la actualidad chilena neoliberal como sociedad que se levanta, sin culpas, sobre sus muertos.

El sujeto protagonista, carente de todo poder fáctico en la sociedad neoliberal, se complace en el recurso de la mirada. Su voyeurismo es intento ilusorio de posesión panóptica del otro (Foucault), en que el observador violenta a quien es observado sin que este lo perciba. En Cartago (2008) ese "darle rienda suelta al fisgoneo" (20) constituye una tentativa sutil del individuo de agenciarse aunque sea un mínimo de su poder perdido para siempre.

Aunque esto es completamente fútil pues el poder efectivo en la sociedad neoliberal lo constituye el dinero, articulador de la violencia sistémica (Žižek). En contraste con el protagonista que apenas sobrevive miserablemente, su antiguo compañero de la escuela militar, Aburto, forma parte de una casta prepotente, acostumbrada a la voz de mando, a la imposición de la obediencia y al desprecio al prójimo, que participó activamente de la violencia durante la dictadura $\mathrm{y}$, sin embargo, en el presente del relato, durante la democracia chilena, goza del nuevo poder de los beneficios económicos. Este le permite complacer los caprichos de su esposa tales como viajes a Miami o la compra de un chalé en un importante barrio residencial, por el solo placer de las apariencias.

Sin embargo, no constituyen las diferencias económicas las que generan la violencia entre ambos ex compañeros, sino su postura contraria sobre el pasado sangriento de la nación y el modo de recordarlo. Slavoj Žižek (2009) asegura que la violencia del crimen conlleva un posicionamiento. Ante la tríada constituida por el castigo, el perdón y el olvido, propone que la solución no radica en el perdón aparente sin olvido para borrar el crimen, sino en el principio de venganza judía o castigo justo que posibilite efectivamente el avance y que el crimen, una vez castigado, pueda quedar en el pasado. En Cartago se evidencia cómo en el Chile reconciliado a la fuerza es cuestionable la identidad entre los sujetos, prevalece el odio contenido y no hay posibilidad de entendimiento ni reconciliación real de intereses entre las partes en conflicto pues el crimen no ha sido castigado. Así el protagonista se empodera de justicia alegórica y asesina por venganza a su ex compañero. El individuo siente que no tiene más opciones que tomarse la violencia por su mano, cuando desde las voluntades de poder hegemónico no se avizoran actitudes condenatorias efectivas hacia el crimen. 
La última visita del protagonista a Villa Grimaldi lo había enfrentado con la construcción de un parque conmemorativo en homenaje a la paz. Hecho que le motiva la reflexión sobre los mecanismos del poder que, luego de la devastación para limpiar los vestigios y "aplanar la historia reciente" (53), se esfuerzan por embellecer el pasado, por la estetización que acabe por aniquilar cualquier vestigio de la violencia. Sin embargo, desde su encierro tras el crimen, y a pesar del control disciplinario y el orden a que es sometido, intuye una posibilidad de violencia futura como despertar nacional: "algún día, la bronca estallará y emergerán cucharas afiladas en sus bordes, se desatarán conatos de incendio mediante los colchones y aparecerán sogas para colgar a los vigilantes" (42), hecho que resuena premonitorio a la luz del presente chileno.

Esta trilogía de Marín evidencia lo ilusorio de la unidad chilena, pues la historia de este país está rota, como asegura Andrea Kottow (2010). Así Un animal mudo levanta la vista transita por la destrucción, pasando por el intento de reconstrucción (adaptación infructuosa al sistema neoliberal), hasta concluir en la total devastación en Cartago. En esta el sujeto recluido pertenece al pasado. Compara su percepción del tiempo con la ciudad de Cartago en los manuales de Historia, como alegoría del olvido a que son sometidos los derrotados. Porque él mismo es un derrotado de la historia, olvidado en su reclusión.

Sin embargo, a pesar de la locura y al resto de sus decadencias, el sujeto en Cartago (2008) salva la memoria, aunque imperfecta, "como una forma de sostén" (31), y con esta la posibilidad escritural. Sus recuerdos fragmentarios, la nostalgia sobre diferentes momentos de la nación, le permiten el encuentro con la escritura para sí mismo, como posibilidad de sobrevivir al trauma de la catástrofe nacional y personal. Esta escritura nostálgica, de duelo y sobrevivencia sobre los escombros del pasado, se aparta drásticamente de lo que constituye la literatura chilena contemporánea al presente en la narración, la cual es criticada por el protagonista por su presentismo desmedido y la superficialidad de sus temas repetitivos que tapian la Historia nacional violenta.

El protagonista, en su trabajo como editor, antes de que fuera internado, intenta subvertir el contenido de uno de los textos que llega a sus manos, relacionado con su propia historia, "improvisando saltos, alteraciones, trampas, que permitieran evadir el destino trazado en dicho manuscrito" (107). De esta manera, Marín posiciona la fragmentación 
como estrategia para que la escritura tenga la posibilidad de hacerle trampas al poder oficial.

Es precisamente la fragmentación residual a lo único que tiene acceso el protagonista desde su reclusión. Una vez allí solo le es posible percibir de la realidad exterior algunas noticias truncas, despedazadas, en una visión caleidoscópica del presente, de subversión temporal. Esto lo lleva a comprender que el presente no es siempre hijo del pasado, o lo que Walter Benjamin (2010) entendiera como romper el continuum de la historia.

Sin embargo, esta ruptura ya no va a ser viable desde la figura alegórica de la ruina, por su imposibilidad en el capitalismo tardío, como explicara Andreas Huyssen (2007). En el Chile que recrea Marín en Un animal mudo levanta la vista predomina el dinamismo neoliberal, la destrucción casi total con escasos restos, la fácil sustitución, el reciclaje, la estetización o reconstrucción amnésica desde las voluntades del poder, para ocultar la violencia pasada y enmascarar la violencia presente en una sociedad decadente. Luego de las promesas de salvación nacional promulgadas por la dictadura, cuyo método violento pretendía justificarse como salvación de la violencia de sus adversarios, para combatir las ruinas a las que llevaría el comunismo, la sociedad chilena del siglo XXI se vislumbra en la trilogía de Marín como fracaso individual y colectivo. Una vez que tras la catástrofe y el trauma de la dictadura solo emergen vestigios, y que la sociedad se encuentra atravesada por mutaciones de la violencia como continuidad del poder dictatorial, la sobrevivencia en la escritura del sujeto residual, como detritus de la historia pero a la vez posibilidad de nuevos sentidos contrapuestos al poder hegemónico, no solo fractura, sino que aniquila el espejismo neoliberal.

\section{La posibilidad de sentido del sujeto contemporáneo}

La poética de Germán Marín expresada en Un animal mudo levanta la vista se concibe sobre un contexto finisecular, transicional, propicio para la aguda reflexión del individuo sobre su realidad. Joseba Zulaika (2006) hace referencia a la preponderancia de la representación mediante la ruina en épocas de cambio de siglo o milenio, así como en momentos históricos de importantes transformaciones económicas o sociales, lo cual es el caso de la obra estudiada. Marín se sabe sujeto contemporáneo al modo que lo entiende 
Giorgio Agamben (2011), por la relación conflictiva con su tiempo histórico, por su desfasaje, anacronismo, su capacidad de distanciarse, de reflexionar y de entender el pasado como embrión del presente. Para Agamben el sujeto contemporáneo "puede odiar su tiempo, pero sabe de todos modos que le pertenece irrevocablemente, sabe que no puede huir de su tiempo" (18). Del mismo modo que su condición de contemporáneo estriba en la crítica aguda capaz de fracturar temporalidades, en no cegarse por las luces epocales, en mantener la mirada en el presente "para percibir, no sus luces, sino su oscuridad" (21). Así la trilogía de Marín escarba en la oscuridad de su realidad, en la cual el individuo contemporáneo experimenta desasosiego y marginación con respecto a las voluntades de poder, así como decadencia residual. La marginación en estas novelas de Marín gravita en la imposibilidad de homogenización del sujeto protagonista en el consumo neoliberal, la desmemoria y la violencia dictatorial trasfigurada. Realidad que lo acerca a otros escritores iberoamericanos, en un espíritu compartido de desilusión y escepticismo.

Es esclarecedor lo postulado por Wolfgang Sofsky (2006), para quien el poder limita cierta violencia social pero él mismo genera el temor hacia la violencia que viene desde el mismo poder (sea democrático o totalitario), basado siempre en la arbitrariedad y el miedo. En las novelas estudiadas las voluntades del poder hegemónico trabajan de formas disimiles; por ejemplo, en la postura de la prensa (no en vano denominada cuarto poder). Esta silencia la violencia y la destrucción. El poder mediático tiene la facultad de hacerse con la realidad mediada. Los medios tienen poder sobre lo que entra o no entra en la realidad y de esta manera manipulan el relato, o crean relato. Sin embargo, detrás de los medios de comunicación siempre hay un poder fáctico. La censura de los medios es una forma alegórica de eliminar al individuo en la nueva realidad, una alegoría que remeda a los desaparecidos en dictadura, una nueva cara contemporánea de la violencia.

Marín elabora una poética que arremete contra las voluntades hegemónicas en Chile que emplean una estrategia de manipulación al pretender arrasar, mediante el olvido, con los horrores del pasado vergonzoso, mediante prácticas de destrucción total en las que no es posible recomponer la realidad fáctica pues esta ha quedado convertida en detritus.

La trilogía de Marín se regodea en la violencia desde variadas aristas, entendiendo esta como evidencia del fracaso de la dictadura como proyecto totalizador, en cuanto presenta en plena democracia los residuos, precariedades y detritus de aquella. De esta 
manera se pone de manifiesto que la represión y la violencia siguen manifestándose, aunque desde la mutación en la década del noventa, con una herencia putrefacta que disfraza el fin comercial; lo que arroja al siglo XXI un individuo más degradado, un despojo decadente y residual.

El análisis de esta trilogía complementa, desde una arista particular, los estudios sobre dictaduras y posdictaduras en Latinoamérica, evidenciando que los sujetos que viven bajo sistemas totalitarios, o sistemas "democráticos" que son el resultado de dichos totalitarismos, oprimidos y violentados desde el poder, comparten una condición residual de fracaso, lo que permite al autor plantear una poética de fragmentación como un modo de trastocar el discurso oficial.

Las novelas de Marín, escritas desde un tono de sobriedad y acidez (que denota una herida abierta que solo puede sanar cuando sobrevenga el castigo), embisten contra el sistema neoliberal, espejismo de bienestar, que aniquila por completo al individuo, sumergiéndolo en la banalidad y la desideologización del capital y el consumo. El sistema neoliberal, a su vez, privilegia el dinamismo y la sustitución o, en el mejor de los casos, el reciclaje y la reconstrucción estetizadora de la violencia. De cualquier manera, siempre prevalece la amnesia por encima de la permanencia, ya sea de objetos, proyectos o ideales. En el contexto de destrucción sobre el que se posiciona el sujeto residual de Marín, no es posible hablar ya de ruinas, sino de detritus, pues tras la catástrofe de la dictadura solo emergen vestigios. Sin embargo, estos son suficientes para el intento de sobrevivencia en la creación.

Jean-Luc Nancy (2003) advierte que en la actualidad ya no es posible hablar de un sentido del mundo homogéneo y unívoco pues "el sentido se encuentra en estado de abandono" (14). Las novelas de Marín sacan a la luz cómo las voluntades de poder intentan imponer un sentido único que violenta al individuo. Sin embargo, la poética de este autor apunta a fracturar esa noción, desde la apertura que se genera desde las posibilidades creativas. El arte, para Nancy, permite la apertura del mundo y del sentido, sirve para "abrir el mundo a sí mismo, a su posibilidad de mundo, a su posibilidad entonces de abrir sentido, mientras que el sentido ya dado está cerrado" (25). La escritura como opción del sujeto decadente en las novelas estudiadas viene a afrontar al poder hegemónico aportando una posibilidad de sentido otro que se constituye en resistencia o sobrevivencia ante el detritus. 
La escritura en Marín se erige como fuerza esperanzadora (aunque mínima) ante el fracaso. La tensión que genera la literatura contra el pragmatismo oficial hace de ella una "forma privada de la utopía" (Piglia 94). La literatura en las novelas de Marín, como "deseo de lo imposible" (Barthes 128), no implica conclusión ni totalidad. Por el contrario, como creación que se resiste al poder hegemónico partiendo de espacios residuales, evocadores de desilusión, derrota y transitoriedad, es alternativa fragmentadora. Esta, si bien no amenaza fácticamente a las voluntades de poder, constituye una alegoría que crea sentidos y propicia la reflexión crítica sobre las causas del deterioro residual, como forma de resistencia o sobrevivencia. De esta manera, una vez que las grandes utopías colectivas totalitarias se han volatilizado, la poética del autor estudiado pondera la fragmentación como destructora de totalidades del sistema hegemónico, desde el detritus, desde la condición de fracaso individual o social pero, igualmente relevante, la posibilidad creativa de resistencia o sobrevivencia ante la oscuridad contemporánea.

\section{FINANCIAMIENTO}

El presente artículo surge en el contexto del Doctorado en Literatura Latinoamericana de la Universidad de Concepción, Chile, con financiamiento de la Beca ANID. Está enmarcado en el proyecto FONDECYT de iniciación No 11170585 "Reflexión y resistencia desde la poética de las ruinas de Germán Marín”, dirigido por la Dra. Mariela Fuentes Leal.

\section{REFERENCIAS}

Agamben, Giorgio. Desnudez. Buenos Aires: Adriana Hidalgo editora, 2011. Impreso. Agamben, Giorgio. El uso de los cuerpos (Homo sacer, IV, 2). Buenos Aires: Adriana Hidalgo editora, 2017. Impreso.

Aguilera Parraguez, Daniela. El proceso de degradación en la memoria y escritura del narrador en Un animal mudo levanta la vista de Germán Marín. Tesis de grado de Licenciatura en Lengua y Literatura Hispánica. Universidad de Chile, 2013. Digital.

Aínsa, Fernando. "Utopías contemporáneas de América Latina". América: Cahiers du CRICCAL 32 (2004): 9-33. Digital.

Avelar, Idelber. Alegorías de la derrota: la ficción postdictatorial y el trabajo del duelo. Santiago: Editorial Cuarto Propio, 2011. Impreso.

Barthes, Roland. El placer del texto. Lección Inaugural. México: Siglo XXI Editores, 1993. Digital.

Benjamin, Walter. Ensayos escogidos. Buenos Aires: El cuenco de plata, 2010. Impreso.

Barreto Moroni, Iván. "La pérdida del origen en el neoliberalismo: Ídola, de Germán Marín”. Cuadernos de ALEPH 2 (2007): 21-46. Digital. 
Costabal Arellano, Soledad Daniela. La narración como proyección del olvido en El palacio de la risa de Germán Marín. Tesis de grado de Licenciatura en Lengua y Literatura Hispánica. Universidad de Chile, 2008. Digital.

Foucault, Michel. Vigilar y castigar. Nacimiento de la prisión. Buenos Aires: Siglo veintiuno editores, 1976. Digital.

Gallardo Villegas, Milena. «No lloro yo por llorar, sino por hallar sosiego». Poética de la memoria traumática en El palacio de la risa del escritor chileno Germán Marín. Tesis de grado de Licenciatura en Lengua y Literatura Hispánica. Universidad de Chile, 2008. Digital.

Giorgi, Gabriel. Formas comunes: Animalidad, cultura, biopolitica. Buenos Aires: Eterna cadencia editora, 2014. Digital.

Han, Byung-Chul. Topología de la violencia. Barcelona: Herder Editorial, 2016. Impreso.

Huyssen, Andreas. "La nostalgia de las ruinas". Punto de Vista 87 (2007): 34-40. Digital.

Kottow, Andrea. "La figura de la pérdida como catástrofe del individuo contemporáneo en la trilogía Un animal mudo levanta la vista de Germán Marín: Una lectura desde Peter Sloterdijk". Acta Literaria 41 (2010): 35-51. Digital.

Marín, Germán. El palacio de la risa. Santiago: Editorial Planeta Chilena, 1995. Impreso.

Marín, Germán. Ídola. Santiago: Editorial Sudamericana Chilena, 2000. Impreso

Marín, Germán. Cartago. Santiago: Random House Mondadori, 2008. Impreso.

Moraña, Mabel. Filosofía y crítica en América Latina: de Mariátegui a Sloterdijk. Santiago: Ediciones Metales Pesados, 2018. Impreso.

Moya, Cristóbal. "Memoria en la Postdictadura chilena: Nocturno de Chile de Roberto Bolaño y El palacio de la risa de Germán Marín”. Ensayo y Error. Primer Coloquio de Estudios Literarios de Pregrado (2009): 185-194. Digital.

Nancy, Jean-Luc. El sentido del mundo. Buenos Aires: La marca editora, 2003. Digital.

Olea Rosenbluth, Catalina. Mujeres y colaboración en tres novelas de la dictadura chilena. Tesis de Magíster en Literatura. Universidad de Chile, 2014. Digital.

Piglia, Ricardo. Crítica y ficción. Barcelona: Anagrama, 2001. Impreso.

Quitral Rojas, Máximo. "Estado, mercado y sociedad en el Chile de los noventa: ¿La herencia de un "modelo de modernización" autoritario?". Atenea 506 (2012): 97-119. Digital.

Rojo, Grínor. "Germán Marín está de visita en El palacio de la risa". A Contracorriente 11: 3 (2014): 297-304. Digital.

Salazar, Gabriel. Villa Grimaldi. (Cuartel Terranova). Santiago: LOM Ediciones, 2013. Impreso.

Simmel, Georg. Sobre la aventura. Barcelona: Ediciones 62, 2002. Digital.

Sofsky, Wolfgang. Tratado sobre la violencia. Madrid: Abada Editores, 2006. Impreso.

Soto Souyris, Bárbara. Ídola: la degradación del intelectual en la ciudad-sexo. Informe de Seminario "El tópico de la ciudad en la narrativa chilena" para optar al grado de Licenciado en Lengua y Literatura Hispánica. Universidad de Chile, 2004. Digital.

Stern, Steve. Luchando por mentes y corazones. Las batallas de la memoria en el Chile de Pinochet. Santiago: Ediciones Universidad Diego Portales, 2013. Impreso.

Willem, Bieke. "Lugares de maravilla y de horror. La imagen de la casa en El palacio de la risa de Germán Marín y Una casa vacía de Carlos Cerda". Amerika 3 (2010). Digital.

Žižek, Slavoj. Sobre la violencia. Seis reflexiones marginales. Buenos Aires: Editorial Paidós, 2009. Digital. 
Zulaika, Joseba. "Las ruinas de la teoría y la teoría de las ruinas: sobre la conversión". Revista de antropología social 15 (2006): 173-192. Digital. 